\title{
Synergic effect of calcium oxide and iron (III) oxide on the dechlorination of hexachlorobenzene
}

\author{
Xiaodong Ma, Minghui Zheng *, Wenbin Liu, Yong Qian, \\ Xingru Zhao, Bing Zhang
}

Key Laboratory of Environmental Chemistry and Ecotoxicology, Research Center for Eco-Environmental Sciences, Chinese Academy of Sciences, P.O. Box 2871, Beijing 100085, China

Available online 6 June 2005

\begin{abstract}
Dechlorination of hexachlorobenzene (HCB) was achieved by a mixture of commercial $\mathrm{CaO}$ and $\alpha-\mathrm{Fe}_{2} \mathrm{O}_{3}(\mathrm{CaO} /$ $\left.\alpha-\mathrm{Fe}_{2} \mathrm{O}_{3}\right)$ in closed systems at temperatures of $300{ }^{\circ} \mathrm{C}$ and $350{ }^{\circ} \mathrm{C}$, which exhibited a synergic effect compared to $\mathrm{CaO}$ or $\alpha-\mathrm{Fe}_{2} \mathrm{O}_{3}$ alone, and the dechlorination efficiency was dramatically enhanced. When $\mathrm{CaO}$ and $\alpha-\mathrm{Fe}_{2} \mathrm{O}_{3}$ coexisted, $\mathrm{HCB}$ was dechlorinated by about $98 \%$ after $0.5 \mathrm{~h}$ reaction at $300^{\circ} \mathrm{C}$. All TeCB-, TrCB-, and DCB-isomers were detected, showing the presence of more than one dechlorination pathway. The pathway to form 1,2,4-TrCB must be a major pathway because the greatest amount of 1,2,4- $\mathrm{TrCB}$ was detected. There existed discrepancy of the material balance between the starting and dechlorinated materials. It implies that besides dechlorination other decomposition processes may be present. The mechanism of synergic effect of calcium and iron oxides was investigated.
\end{abstract}

(C) 2005 Elsevier Ltd. All rights reserved.

Keywords: Dechlorination; $\mathrm{HCB} ; \mathrm{CaO} ; \alpha-\mathrm{Fe}_{2} \mathrm{O}_{3}$; Synergic effect

\section{Introduction}

It is well known that halogenated organic compounds have been used on a large scale in the chemical, petrochemical, and electronic industries. Due to leak and release from industrial sources, they inevitably contaminate environments such as soil and groundwater. The disposal of organic wastes containing halogen has become a major environmental and social problem, because most of them are toxic and very stable, accumulating in the surrounding for long periods. Polychlorinated

\footnotetext{
* Corresponding author. Tel.: +86106284 9172; fax: +8610 62923563.

E-mail address: zhengmh@mail.rcees.ac.cn (M. Zheng).
}

aromatic compounds are environmentally persistent chemicals, recalcitrant toward degradation, which bioaccumulate in fatty tissue and show carcinogenic and mutagenic activity, so they are a class of pollutants of special environmental concern (Alonso et al., 2002).

The most extensively used method to destroy unwanted chlorocarbons is by incineration (Lee and Huffman, 1989; Hawnrl et al., 1992). Toxic chlorinated compounds appear to be completely destroyed by high-temperature thermal oxidation; however, it is related to the release of even more toxic compounds such as chlorinated dioxins and furans. The development of a highly efficient, safe alternative technology for detoxifying organic halides has been anticipated.

Reductive methods can be considered as alternatives to be taken into account prior to their safe but 
controversial incineration. Electrochemical (Wirtz et al., 2000; Atsushi and Akio, 2003), photochemical (Betterton et al., 2000; Hu et al., 2000), ultrasonic (Hung and Hoffmann, 1998; Lin and Ma, 1999), microbial (Chang et al., 1998), radiolytic and thermal (Yamamoto and Tagawa, 2001) reductive methods have been reported. The chemical reduction of organic halides involving the replacement of halogen by hydrogen is the so-called hydrogenolysis of the carbon-halogen bond or hydrodehalogenation reaction, which is known to be promoted by noble metals of group VIII. Literature data have shown that successful dechlorination of polychlorinated aromatic compounds by using $\mathrm{Ni}$ catalysis requires severe reaction conditions, high temperature and high hydrogen pressure. $\mathrm{Pd}, \mathrm{Ru}$ catalysis permitting successful dechlorination of polychlorinated aromatic compounds under mild conditions is not adapted to large-scale applications because of their high cost (Hagh and Allen, 1990).

In related work, some methods have been reported in regard to metal oxide method. Representative ones include the following: oxidative catalysis over metal oxides and noble metals, for example, catalytic decomposition of hydrochlorocarbons over high surface area $\gamma$-alumina (Ballinger et al., 1992). Iron (III) oxide as a destructive reagent was used to decompose carbon tetrachloride (Hooker and Klabunde, 1994) and PCDD/F (Weber et al., 2002).

Previous studies have revealed that the presence of $\mathrm{CaO}$ allows the destruction of chlorinated benzenes at lower temperatures than simple pyrolysis or combustion processes ( $\mathrm{Li}$ et al., 1994). While, even $\mathrm{CaO}$ particles with very large surface areas was employed, the reaction temperature was still higher than $500{ }^{\circ} \mathrm{C}$ in the $\mathrm{H}_{2}$ atmosphere for decomposing completely. If in the air, the temperature was even greater.

An additional promising method that at relatively low temperatures $\left(400-500^{\circ} \mathrm{C}\right)$ converts halocarbons to $\mathrm{CO}_{x}$ and calcium halides in one step was reported. The process is based on $\mathrm{X}^{-} / \mathrm{O}^{2-}$ exchange on the surface of $\mathrm{CaO}$ (or $\mathrm{MgO}$ or $\mathrm{Fe}_{2} \mathrm{O}_{3}$ ). Thus, oxidizing conditions are not needed. Since the process is based on a surface solid-gas reaction, large surface areas and intrinsic reactivities are beneficial. Ultrafine (nanoscale) particles of $\mathrm{CaO}$ has been synthesized and studied for destruction of chlorocarbons (Koper and Klabunde, 1993; Koper et al., 1997). In the temperature range of $300-500{ }^{\circ} \mathrm{C}$, solid nanocrystalline oxides react nearly stoichiometrically with numerous halocarbons. By the presence of a small amount of transition-metal oxide as catalyst, for example, $\mathrm{Fe}_{2} \mathrm{O}_{3}$ on $\mathrm{CaO}$, the reaction efficiencies can be improved. However the cost of preparation of nanocrystalline oxides is high and synthetic method is complicated. Few studies on polychlorinated aromatic compounds were conducted.

The purpose of this study was to present investigation on the synergic effect of commercial $\mathrm{CaO}$ and $\alpha$ $\mathrm{Fe}_{2} \mathrm{O}_{3}$ on the dechlorination of hexachlorobenzene which was taken as a model compound of polychlorinated aromatic hydrocarbons, and to investigate a predominant dechlorination pathway. The mechanism of synergic effect of calcium and iron oxides was discussed.

\section{Experimental}

\subsection{Materials}

Hexachlorobenzene, hexane, $\mathrm{CaO}$ and $\alpha-\mathrm{Fe}_{2} \mathrm{O}_{3}$ were all analytical grade. $\mathrm{CaO}$ was ground to $\sim 300$ mesh, and heated at $900{ }^{\circ} \mathrm{C}$ for 2 h. $\alpha-\mathrm{Fe}_{2} \mathrm{O}_{3}$ was $\sim 300$ mesh, and was heated at $120^{\circ} \mathrm{C}$ for $2 \mathrm{~h}$.

\subsection{Dechlorination of $\mathrm{HCB}$}

$2.0 \mathrm{mg}$ of $\mathrm{HCB}$ was added to $200 \mathrm{mg} \mathrm{CaO} / \mathrm{Fe}_{2} \mathrm{O}_{3}$, or $200 \mathrm{mg} \mathrm{CaO}$ and $200 \mathrm{mg} \mathrm{Fe}_{2} \mathrm{O}_{3}$, respectively. The mixture was transferred into a small glass tube $(11 \mathrm{~cm}$ length, $0.4 \mathrm{~cm}$ i.d.), which was then sealed under air atmosphere and was heated in an oven. Dechlorination experiments were performed at $300{ }^{\circ} \mathrm{C}$ or $350{ }^{\circ} \mathrm{C}$. Details of reaction conditions were shown in Table 1 .

\subsection{Sample analysis}

After finishing the dechlorination reaction, the glass tubes were cooled to the room temperature, wrapped by aluminum foil, and then they were carefully crushed and subjected to extraction. The samples were extracted with $15 \mathrm{ml}$ hexane twice for 15-20 min each time in an ultrasonic extractor. The solutions were transferred into a separatory funnel and then each solution was washed

Table 1

Reaction conditions for dechlorination of $\mathrm{HCB}$

\begin{tabular}{lcccrr}
\hline & Run 1 & Run 2 & Run 3 & Run 4 & Run 5 \\
\hline Amount of $\mathrm{HCB}(\mathrm{mg})$ & 2 & 2 & 2 & 2 & 2 \\
Amount of $\mathrm{CaO}(\mathrm{mg})$ & 200 & 0 & 100 & 100 & 100 \\
Amount of $\mathrm{Fe}_{2} \mathrm{O}_{3}(\mathrm{mg})$ & 0 & 200 & 100 & 100 & 100 \\
Reaction temperature $\left({ }^{\circ} \mathrm{C}\right)$ & 300 & 300 & 300 & 300 & 350 \\
Period of heating $(\mathrm{h})$ & 1 & 1 & 0.5 & 1 & 1 \\
\hline
\end{tabular}


three times with $15 \mathrm{ml}$ of water. The hexane layers were dried with anhydrous sodium sulfate. The solution was used for the measurement of parent HCB remaining and lower chlorinated benzenes newly formed. The analyses of chlorobenzenes were performed by an Agilent 6890 gas chromatograph equipped with a DB-5 capillary column ( $30 \mathrm{~m}$ length, $0.25 \mathrm{~mm}$ i.d., $0.25 \mu \mathrm{m}$ film thickness) and interfaced to Agilent 5973N MSD. Quantitative analyses of chlorobenzenes were performed in selected ion monitoring mode using two most abundant ions of the molecular ion clusters.

\section{Results and discussion}

\subsection{Yield of dechlorination}

The dechlorination efficiency (DE, \%) was calculated using Eq. (1).

$\mathrm{DE}=1-\frac{\sum_{i=0}^{6} i N_{i}}{6 N_{0}}$

where $N_{i}$ is the molar number of chlorinated benzene containing $i$ chlorine atoms in the molecule and $N_{0}$ is the initial molar number of HCB. The results were demonstrated in Fig. 1. The intermediates formed in the experiments were given in Table 2 .

\subsection{Dechlorination of $\mathrm{HCB}$ by $\mathrm{CaO}$}

It could be seen from Table 2 that HCB was partially dechlorinated by $\mathrm{CaO}$ (Run 1). After $1 \mathrm{~h}$ reaction, the dechlorination efficiency was up to $52 \%$, while the only intermediate was trace amounts of pentachlorobenzene, and no lower chlorinated benzenes were detected. This means that besides dechlorination, other degradation

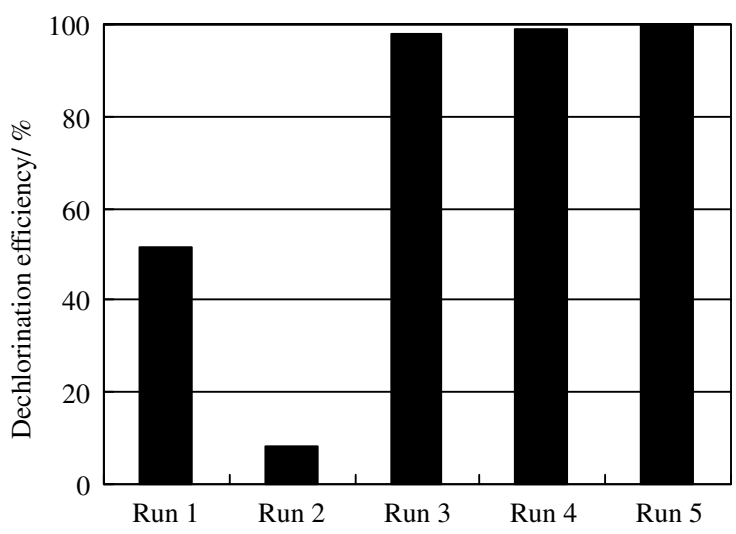

Fig. 1. Dechlorination efficiency in the different experiments.

processes may be present. Similar conclusion was also drawn by Li et al. (1994).

\subsection{Dechlorination of $\mathrm{HCB}$ by $\alpha-\mathrm{Fe}_{2} \mathrm{O}_{3}$}

$\alpha-\mathrm{Fe}_{2} \mathrm{O}_{3}$ has been used as a destructive reagent for chlorinated organic compounds (Hooker and Klabunde, 1994). The reaction was carried out between 400 and $620^{\circ} \mathrm{C}$. The higher activity of $\alpha-\mathrm{Fe}_{2} \mathrm{O}_{3}$ than other metal oxides was found, this can be attributed to the formation of $\mathrm{Fe}_{2} \mathrm{Cl}_{6}$, a dominant vapor species in the vaporization of solid $\mathrm{FeCl}_{3}$. The formation and migration of $\mathrm{FeCl}_{3}$ out of the hot zone are rather rapidly since solid $\mathrm{FeCl}_{3}$ is known to decompose at about $315^{\circ} \mathrm{C}$. In the case of Run 2, due to the reaction temperature was lower $\left(300{ }^{\circ} \mathrm{C}\right)$, the dechlorination pathway became less efficient. Dechlorination efficiency was just about $8.4 \%$. A tentative explanation is that the surface of the $\mathrm{Fe}_{2} \mathrm{O}_{3}$ be-

Table 2

Comparison of the amount of formed products in the dechlorination of $\mathrm{HCB}^{\mathrm{a}}(\mathrm{nmol})$

\begin{tabular}{|c|c|c|c|c|c|}
\hline Chlorobenzenes & Run 1 & Run 2 & Run 3 & Run 4 & Run 5 \\
\hline $1,3-\mathrm{DCB}$ & $\mathrm{ND}^{1}$ & $\mathrm{ND}^{1}$ & 4.9 & $\mathrm{ND}^{1}$ & $\mathrm{ND}^{1}$ \\
\hline $1,4-\mathrm{DCB}$ & $\mathrm{ND}^{1}$ & $\mathrm{ND}^{1}$ & 4.8 & $\mathrm{ND}^{1}$ & $\mathrm{ND}^{1}$ \\
\hline $1,2-\mathrm{DCB}$ & $\mathrm{ND}^{1}$ & $\mathrm{ND}^{1}$ & 4.5 & $\mathrm{ND}^{1}$ & $\mathrm{ND}^{1}$ \\
\hline $1,2,4-\operatorname{TrCB}$ & $\mathrm{ND}^{2}$ & $\mathrm{ND}^{2}$ & 33 & 74 & $\mathrm{ND}^{2}$ \\
\hline $1,3,5-\operatorname{TrCB}$ & $\mathrm{ND}^{2}$ & $\mathrm{ND}^{2}$ & 6.2 & 18 & $\mathrm{ND}^{2}$ \\
\hline $1,2,3-\operatorname{TrCB}$ & $\mathrm{ND}^{2}$ & $\mathrm{ND}^{2}$ & 4.4 & 6.6 & $\mathrm{ND}^{2}$ \\
\hline $1,2,4,5-\mathrm{TeCB}$ & $\mathrm{ND}^{3}$ & $\mathrm{ND}^{3}$ & 17 & 8.5 & $\mathrm{ND}^{3}$ \\
\hline $1,2,3,5-\mathrm{TeCB}$ & $\mathrm{ND}^{3}$ & $\mathrm{ND}^{3}$ & 16 & 9.4 & $\mathrm{ND}^{3}$ \\
\hline $1,2,3,4-\mathrm{TeCB}$ & $\mathrm{ND}^{3}$ & $\mathrm{ND}^{3}$ & 9.2 & 3.3 & $\mathrm{ND}^{3}$ \\
\hline $\mathrm{PeCB}$ & 48 & $\mathrm{ND}^{4}$ & 49 & 6.8 & $\mathrm{ND}^{4}$ \\
\hline$\sum \mathrm{DPs}^{\mathrm{b}}$ & 48 & - & 149 & 127 & - \\
\hline $\mathrm{HCB}$ & 3724 & 6431 & 54 & 1.8 & $\mathrm{ND}^{4}$ \\
\hline
\end{tabular}

$\mathrm{ND}^{1}<0.8 \mathrm{nmol} ; \mathrm{ND}^{2}<0.3 \mathrm{nmol} ; \mathrm{ND}^{3}<0.2 \mathrm{nmol} ; \mathrm{ND}^{4}<0.1 \mathrm{nmol}$.

${ }^{\mathrm{a}}$ Initial amount of HCB was $7023 \mathrm{nmol}$.

b $\sum \mathrm{DPs}=$ sum of dechlorination products. 
came covered with chloride ions which inhibited further dechlorination. Comparing the dechlorination efficiency in Run 1 and Run 2, the conclusion can be drawn that at lower temperature, $\mathrm{CaO}$ is a better dechlorination agent than $\alpha-\mathrm{Fe}_{2} \mathrm{O}_{3}$.

The difference of dechlorination capacity between $\mathrm{CaO}$ and $\alpha-\mathrm{Fe}_{2} \mathrm{O}_{3}$ could be resulted from the difference of alkalinity. The higher the alkalinity, the higher the dechlorination capacity is.

\subsection{Synergic effect of $\mathrm{CaO} / \alpha-\mathrm{Fe}_{2} \mathrm{O}_{3}$ on the dechlorination of $\mathrm{HCB}$}

From the analytical results of intermediate chlorobenzenes in Run 3, it was found that the dechlorination capacity increased greatly when $\mathrm{CaO}$ and $\alpha-\mathrm{Fe}_{2} \mathrm{O}_{3}$ coexisted. The residual amount of $\mathrm{HCB}$ was only $54 \mathrm{nmol}$, much less than the original 7023 nmol. Dechlorination efficiency was about $98 \%$. Comparing the data in Run 3, Run 4, and Run 5, one can observe that the dechlorination was greater with increasing reaction time or temperature. At $300{ }^{\circ} \mathrm{C}$ for $1 \mathrm{~h}$, the dechlorination extent was up to $99 \%$, and $100 \%$ at $350{ }^{\circ} \mathrm{C}$ for $1 \mathrm{~h}$.

$\mathrm{CaO}$ and $\alpha-\mathrm{Fe}_{2} \mathrm{O}_{3}$ exhibits a remarkable synergic effect on the dechlorination of HCB. Decreasing orders of chlorobenzenes by amount were $1,2,4,5-\approx 1,2,3,5->$ 1,2,3,4- for tetrachlorobenzenes (TeCB); 1,2,4- > 1,3,5- > 1,2,3- for trichlorobenzenes ( $\mathrm{TrCB}$ ); the amount of 1,3-, 1,4-, 1,2-dichlorobenzene (DCB) were almost the same. The pathway to form 1,2,4-TrCB must be a major pathway because the greatest amount of 1,2,4-TrCB was detected. All TeCB-, TrCB-, and DCB-isomers were detected, showing the presence of more than one dechlorination pathway.

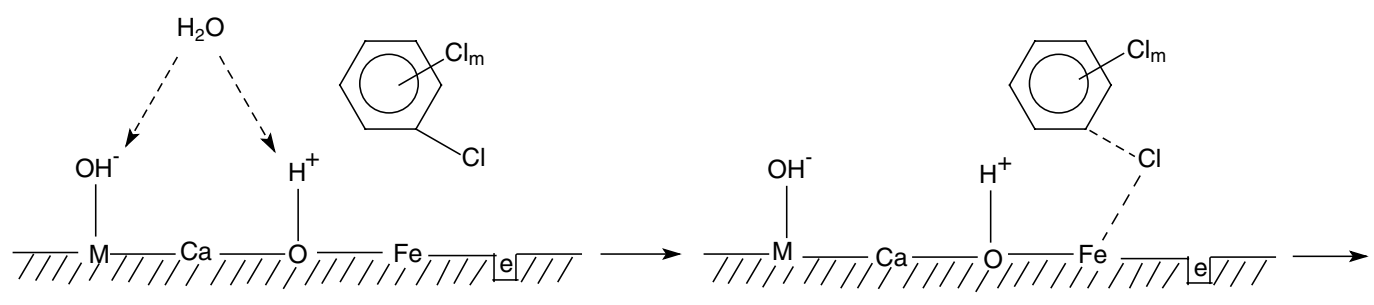

idealized interface $(\mathrm{m}=0-5)$
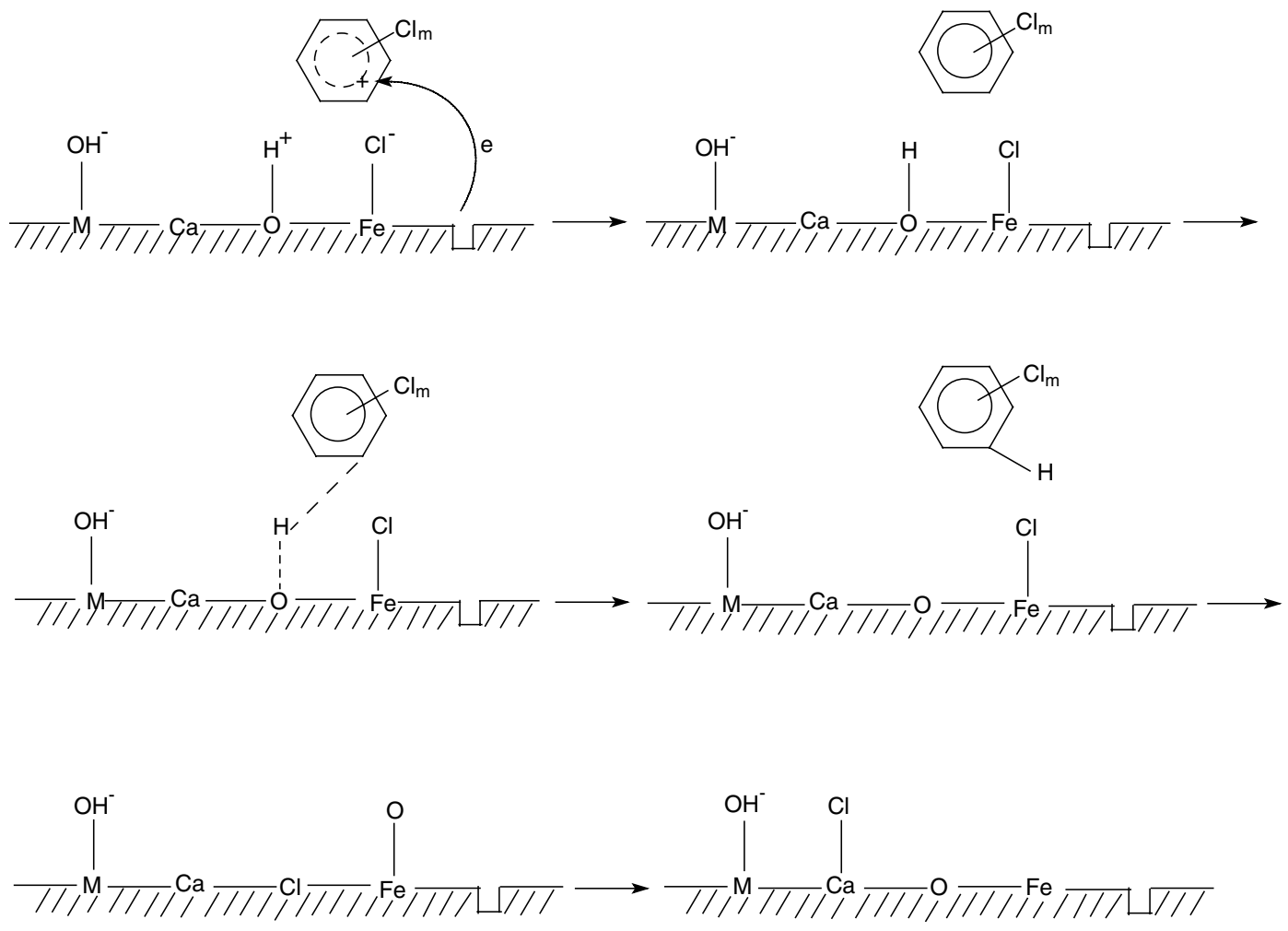

Fig. 2. A proposed mechanism for the dechlorination of $\mathrm{HCB}$ over the solid surface of $\mathrm{CaO} / \alpha-\mathrm{Fe}_{2} \mathrm{O}_{3}$. 
When $\mathrm{HCB}$ was dechlorinated by $\mathrm{CaO} / \alpha-\mathrm{Fe}_{2} \mathrm{O}_{3}$, there existed discrepancy in the material balance of the starting and dechlorinated materials. This implies besides dechlorination other decomposition processes may be present. Similar conclusion was also made by Schoonenboom et al. (1995).

Previous studies have revealed that $\mathrm{CaO}$ could improve the decomposition of chlorinated hydrocarbons over iron oxide catalysis (Jiang et al., 1998; Decker et al., 2002). This effect is attributed to ion exchange between the $\mathrm{CaO}$ and $\mathrm{FeCl}_{3}$, the latter being formed as a result of interaction of iron oxide with chlorinated hydrocarbons. In that case, calcium servers as a sink for chlorine ions, regenerating iron oxide. For efficient chloride ion exchange between iron and calcium in an interfacial process, good contact between the phases is necessary. The systems discussed in the previous paper (Decker et al., 2002) were composed of transition-metal oxides $(\mathrm{Fe}, \mathrm{Ni})$ supposed on $\mathrm{CaO}$ with intimate contact. In the case of this study, due to the mean particle is relatively larger $(50 \mu \mathrm{m})$, the surface area is smaller, so the content of oxides used is excessive in order to ensure interface between iron oxide and calcium oxide.

It is known that metallic ions and $\mathrm{O}^{2-}$ on the surfaces of metal oxides are unsaturated according to the coordination theory. They are prone to bond with some functional groups that are absorbed as ligands. $\mathrm{For} \mathrm{Fe}_{2} \mathrm{O}_{3}$ belongs to $\mathrm{N}$ type semiconductor, some electrons exist in the vacancies that are from defection of surface $\mathrm{O}^{2-}$. Water absorbed is dissociated to produce $\mathrm{OH}^{-}$and $\mathrm{H}^{+}$, and they bond with metallic ions and $\mathrm{O}^{2-}$, respectively.

On the basis of these established theories, a possible mechanism for the dechlorination of $\mathrm{HCB}$ with $\mathrm{CaO} /$ $\alpha-\mathrm{Fe}_{2} \mathrm{O}_{3}$ is illustrated (Fig. 2). An idealized interface of $\mathrm{CaO} / \alpha-\mathrm{Fe}_{2} \mathrm{O}_{3}$ is given. It is reasonable to assume a synergic effect of calcium and iron oxides. We speculate that unsaturated iron ions at the surface serve as an initial adsorption sites for HCB, which leads to the breakage of $\mathrm{C}-\mathrm{Cl}$ bond. Chlorine ions on the iron surface as well as carbonium ions were produced simultaneously. At the next step, electrons from the vacancies of iron oxide are transferred to benzene ring to cause the displacement of $\mathrm{H}^{+}$from the linkage with ligand $\mathrm{O}^{2-}$, to form $\mathrm{PeCB}$. The newly formed chloride ion can then migrate over the surface of the particle to perform $\mathrm{Cl}^{-} / \mathrm{O}^{2-}$ exchange. Calcium servers as a sink for chlorine ion in the process of dechlorination. The displacement of chlorine is repeated, until all chloride atoms are converted.

\section{Acknowledgments}

This study was supported by National Basic Research Program of China (Grant No. 2003CB415006) and National Natural Science Foundation of China (Grant Nos. 20177031, 20122202).

\section{References}

Alonso, F., Beletskaya, I.P., Yus, M., 2002. Metal-mediated reductive hydrodehalogenation of organic halides. Chem. Rev. 102, 4009-4091.

Atsushi, M., Akio, Y., 2003. Complete dechlorination of 1chloronaphthalene by electrochemical reduction with nanophthalene radical anion as mediator. Environ. Sci. Technol. 37, 3435-3441.

Ballinger, T.H., Yates Jr, J.T., 1992. Interaction and catalytic decomposition of 1,1,1-trichloroethane on high surface area alumina: An infrared spectroscopic study. J. Phys. Chem. 96, 1417-1423.

Betterton, E.A., Hollan, N., Zhijie, L., 2000. Acetone-photosensitized reduction of carbon tetrachloride by 2-propanol in aqueous solution. Environ. Sci. Technol. 34, 12291233.

Chang, B.V., Su, C.J., Yuan, S.Y., 1998. Microbial hexachlorobenzene dechlorination under three reducing conditions. Chemosphere 36, 2721-2730.

Decker, S.P., Klabunde, J.S., Khaleel, A., Klabunde, K.J., 2002. Catalyzed destructive adsorption of environmental toxins with nanocrystalline metal oxides. Fluoro-, chloro-, bromocarbons, sulfur, and organophosophorus compounds. Environ. Sci. Technol. 36, 762-768.

Hagh, B.F., Allen, D.T., 1990. Catalytic hydroprocessing of chlorinated benzenes. Chem. Eng. Sci. 45, 2695-2701.

Hawnrl, J., Demeter, A., Samson, R., 1992. Sensitized photolysis of polychlorobiphenyls in alkaline 2-propanol: Dechlorination of aroclor 1254 in soil samples by solar radiation. Environ. Sci. Technol. 26, 2022-2027.

Hooker, P.D., Klabunde, K.J., 1994. Destructive adsorption of carbon tetrachloride on iron (III) oxide. Environ. Sci. Technol. 28, 1243-1247.

Hu, C.W., Yue, B., Yamase, T., 2000. Photoassisted dehalogenation of organochlorine compounds by paratungstate A in aqueous solution. Appl. Catal., A: Gen. 194-195, 99-107.

Hung, H.M., Hoffmann, M.R., 1998. Kinetics and mechanism of enchanced reductive degradation of $\mathrm{CCl}_{4}$ by elemental iron in the presence of ultrasound. Environ. Sci. Technol. 32, 3011-3016.

Jiang, Y., Decker, S., Mohs, C., Klabunde, K.J., 1998. Catalytic solid state reactions on the surface of nanoscale metal oxide particles. J. Catal. 180, 24-35.

Koper, O., Klabunde, K.J., 1993. Destructive adsorption of chlorinated hydrocarbons on ultrafine (nanoscale) particles of calcium oxides. Chem. Mater. 5, 500-505.

Koper, O., Lagadic, I., Klabunde, K.J., 1997. Destructive adsorption of chlorinated hydrocarbons on ultrafine (nanoscale) particles of calcium oxide 2. Chem. Mater. 9, 838-848.

Lee, C.C., Huffman, G.L., 1989. Innovative thermal destruction technologies. Environ. Prog. 8, 190-199.

Li, Y.X., Li, H., Klabunde, K.J., 1994. Destructive adsorption of chlorinated benzenes on ultrafine (nanoscale) particles of magnesium oxide and calcium oxide. Environ. Sci. Technol. 28, 1248-1253.

Lin, J.G., Ma, Y.S., 1999. Magnitude of effect of reaction parameters on 2-chlorophenol decomposition by ultrasonic process. J. Hazard. Mater. 66, 291-305.

Schoonenboom, M.H., Zoetemeijer, H.E., Olie, K., 1995. Dechlorination of octachlorodibenzo-p-dioxin and octa- 
chlorodibenzofuran on an alumina support. Appl. Catal. B Environ. 6, 11-20.

Weber, R., Nagai, K., Nishino, J., Shiraishi, H., Ishida, M., Takasuga, T., Konndo, K., Hiraoka, M., 2002. Effects of selected metal oxides on the dechlorination and destruction of PCDD and PCDF. Chemosphere 46, 1247-1253.
Wirtz, M., Klucik, J., Rivera, M.J., 2000. Ferredoxin-mediated electrocatalytic dechlogenation of haloalkanes by cytochrome P450 cam. J. Am. Chem. Soc. 122, 1047-1056.

Yamamoto, Y., Tagawa, S., 2001. Radiolytic and thermal dechlorination of organic chlorides adsorbed on molecular sieve 13X. Environ. Sci. Technol. 35, 2122-2127. 